\title{
Fluorescent Biosensors for Protein Interactions and Drug Discovery
}

\author{
Alejandro Sosa-Peinado ${ }^{1}$ and Martín González-Andrade ${ }^{2}$ \\ ${ }^{1}$ Departamento de Bioquímica, Facultad de Medicina, \\ Universidad Nacional Autónoma de México \\ ${ }^{2}$ Facultad de Química, \\ Universidad Nacional Autónoma de México \\ México
}

\section{Introduction}

The powerful ability of proteins to bind selectively its ligand and interact specifically with other proteins during its functions, have been employed in the development of highly specific and robust biosensors (Medintz and Deschamps 2006; Vallee-Belisle and Plaxco 2010). To design protein biosensor is required to attach a transducer to the protein in order to monitor a specific interaction. The nature of this transducer is diverse, but fluorescent attachment has been used extensively by protein, in general are based in attachment in a the chemical groups and/or in the genetical fusion of green fluorescent proteins (GFP) or derived proteins (Deuschle, Okumoto et al. 2005; Campbell 2009; Wang, Nakata et al. 2009). In this review we are focus in the fluorescent biosensors based in site-specific fluorescent labeling, as a result of combining the chemical attachment by site-directed mutagenesis and/ or manipulation of genetic code. Given the enormous diversity in the nature of the fluorescent attachment to proteins, we are focused to the recent advances in monitoring protein-ligand and protein-protein, and their applications in different areas of research. Since the protein scaffold used as biosensor might be a pharmacological target (Cooper 2003), the design of robust biosensors, could be used for high-throughput screening in the search of new drugs (Cooper 2003).

\section{General design of biosensor}

A biosensor is a biological receptor able to monitor the concentration of a specific analyte or even more, could be selective to interact only with a particular conformation of a macromolecule, event typically associated to the allosteric proteins, that present changes in the protein conformation coupled to changes in the affinity for its ligand or another proteins (Wang, Nakata et al. 2009). In any case, for the biosensor design is required their appropriate transducer, and the nature of this could be diverse: optic, mechano-chemical, electro-chemical, acustic, etc. There is no a universal rationale for biosensor construction, therefore, should be taken in consideration several features for design: First, is the choice for the biological component, in general is a protein that provide the stereospecificity 
required for the wanted interaction, but in some cases nucleic acids are good sensors (aptamers). Enzymes are very specific, however in some cases the catalysis is not desirable, thus some enzymes have to be modified to impair the activity and conserve only the ligand binding property, or the ideal case is to use a protein that only bind the analyte to monitor. Accordingly, a family of proteins in the periplasmic space of bacteria fulfill the last requirement (Looger, Dwyer et al. 2003; de Lorimier, Tian et al. 2006). These proteins named periplasmic binding proteins (PBPs), present a conformational change upon ligand binding, as a first step to interact with a membrane transporters (ABC proteins), previous of the translocation of ligand to the interior to the cell (de Lorimier, Tian et al. 2006; Medintz and Deschamps 2006; Tsukiji, Miyagawa et al. 2009). The different members of these proteins are able to bind a large number of analytes, such a as: carbohydrates, amino acids, ions, hormones, heme-groups, etc. Thus several PBPs has been used to detect a specific ligand, the group of Hellinga has been able to construct constructed several fluorescent biosensors .

The Second consideration, is about the chemical nature of the fluorescent transducer, and the physicochemical property for which the signal is optimal. There are signals very sensitive to the polarity of the solvent, or to the electrochemical environment, $\mathrm{pH}$, etc. In general several fluorescent groups have solvatochromic effects in which there is a low emission fluorescence in aqueous environment, but in low polar environment there is an increase of fluorescence emission associated to a blue-shifted emission spectrum. Since, when a protein interaction take place, this produce changes in solvent accessibility rearrangement of not covalent interaction, thus in many cases the fluorophore may sense the environment perturbation produced by the protein interaction. Also, there are fluorescents signals that are quenched when a ligand or another protein are in proximity of the label. When the protein present a notable conformational change, in some cases a pair donatoracceptor signals could be selected to generate Foster resonance energy transfer (FRET) biosensors, in which the fluorescence transference energy observed by fluorescence emission changed in a distance dependence when the conformational change take place.

Third consideration, is the selection of a position into the protein to introduce the signal, these position would generate low perturbation in the stability of the protein with full capacity to the specific interaction sought, and high sensitivity for detection, the advantage for label introduction by chemical methods, allow to introduce the label at any position of the protein. This may be the most difficult problem to predict the best place to introduce the signal to produce the high sensitive signal with a low perturbation of the ligand binding system. In many cases when the introduction of the signal is closer of the ligand binding site, allow the good signal. Now days, the structural information of proteins allow to evaluate in silico the effect of protein stability before the experimental work, from the protein data base (PDB), and the identification of structural binding motives or the ability to create a structural model from the homologues protein with know structure in combination with molecular modelling. A fourth factor to be considered is the robustness of the biosensor, to be reproducible, reversible, rapid for signal detection, and reagent free, altogether, these characteristics will determine if the designed biosensor could be able to monitor in real time in either cell environment or in a immobilized device (Looger, Dwyer et al. 2003; ValleeBelisle and Plaxco 2010; Plaxco and Soh 2011). In general there are some advantage and limitations for these type of biosensors (Table 1). 


\begin{tabular}{|c|c|c|}
\hline & Advantage & Limitation \\
\hline Fluorescent groups & $\begin{array}{l}\text { The chemical nature is } \\
\text { diverse, many are } \\
\text { commercial available, is } \\
\text { possible to select a broad } \\
\text { range in light excitation in } \\
\text { the UV, visible spectra. Are } \\
\text { small and is possible to } \\
\text { label at any position into } \\
\text { the protein sequence. }\end{array}$ & $\begin{array}{l}\text { The stability perturbation } \\
\text { that may introduce the } \\
\text { chemical group into the } \\
\text { protein. }\end{array}$ \\
\hline Position for labeling & $\begin{array}{l}\text { Combined with the site } \\
\text { directed mutagenesis is } \\
\text { possible to introduce at any } \\
\text { position wanted. }\end{array}$ & $\begin{array}{l}\text { Stability perturbation, and } \\
\text { undesired reaction, but this } \\
\text { is overcome with } \\
\text { incorporation of SH groups } \\
\text { at specific positions. }\end{array}$ \\
\hline Biological receptor & $\begin{array}{l}\text { There are many ligand } \\
\text { binding proteins, receptor, } \\
\text { and enzymes for protein } \\
\text { selection. }\end{array}$ & $\begin{array}{l}\text { Modification of the ligand } \\
\text { binding specificity for its } \\
\text { ligand. }\end{array}$ \\
\hline
\end{tabular}

Table 1. Advantge and limitation for the inytroduction of fluorescent labels.

\section{Biosensor based in chemical attachment of labels and genetic methods}

The incorporation of fluorescent labels by combination of chemical-labeling methods simultaneously with molecular genetic methods are diverse, nonetheless, we can categorize in three major groups in terms of the method to label the chemical probe into the protein surface: i) incorporation of reactive free cysteine for thiol-fluorescent labeling by site directed labeling methods; ii) site specific incorporation of unnatural fluorescent amino acid based in a expansion of genetic code methods; and iii) incorporation by covalent chemical modification, some by post-photoaffinity labeling from the site directed labeling based in a thiol -fluorescent reactive, the signal incorporation could be at binding site (endosteric), outsite of the binding site (allosteric) or in the case of two fluorophores for fluorescence resonance energy transference (FRET) as described in Fig 1.

\subsection{Biosensor based in site-directed mutagenesis and site-specific fluorescent labeling methodology}

The addition of fluorescent signal to a protein by introduction of a reactive cysteine for a thiol-fluorescent group is consequence of both, the enormous chemical synthesis available to attach covalently fluorescent groups to the $\mathrm{SH}$ group present in the cysteine residue of proteins, and at the same time the well established molecular genetic methods to introduce a new residue by site directed mutagenesis. In particular the thiol groups of a cysteine is the most reactive nucleophile of protein residues, thus, is very effective to label only the $\mathrm{SH}$ residues without non-specific labeling. The large number of fluorescent probes could be excited in a broad range of light wavelength from the uv light to the visible range, and 
A

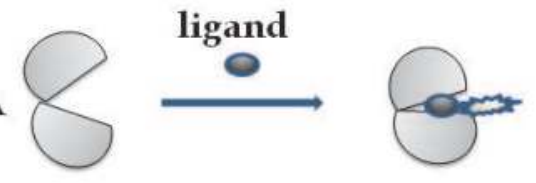

B
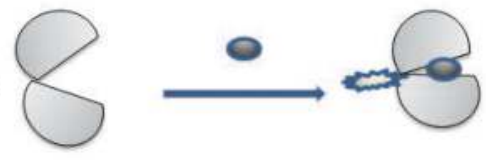

C
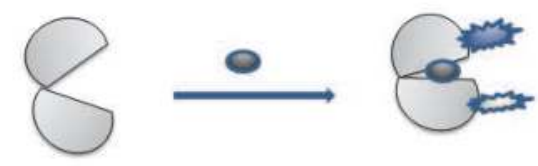

Fig. 1. Localization for fluorescent labeling. A, at the binding site, B, in allosteric site, and C, two fluorophore incoporation for FRET, when the distance between two signals changed by a conformational change..

several of these probes are commercially available (Toronto Chemical Research Inc., Invitrogen-Molecular Probes ${ }^{\mathrm{TM}}$, Sigma-Aldrich $\left.{ }^{\circledR}\right)$. The cysteine residue are not frequently present in proteins, then, is possible eliminate cysteine residues by site directed mutagenesis to avoid unspecific labeling. Site specific labeling of proteins with fluorescent probes, requires careful choice of labeling chemistry, optimization of the labeling reaction, the complete characterization of labeled proteins for: labeling efficiency, retention of protein functionality and minimal structural perturbation (Altenbach, Klein-Seetharaman et al. 1999; Mansoor and Farrens 2004). Given that several of the labels are small chemical groups, the labeling at relatively exposed residues minimize the perturbation in the protein structure. This was demonstrated by Farrens and col by the specific incorporation of bromobimane in a helix-turn-helix motive after chemical modification of 21 consecutive single-cysteine mutants; the residues T115 to K135 of T4 lysozyme. The $\Delta \Delta \mathrm{G}$ calculated from each 21 mutants and compared with the wild type enzyme indicated a minimal energy perturbation $\leq 1.5 \mathrm{kcal} / \mathrm{mol}$, for those residues exposed $\geq 40 \AA$ of solvent surface accessible, after chemical modifications. In this work was pointed out no energy destabilization of $\mathrm{T} 4$ lysozyme after fluorophore labeling unless the residue was buried into the protein structure. Thus having information about the protein topology, or the structure ligand binding domain, there is a good possibility to introduce a small fluorescent signal with low perturbation in the designed protein.

\subsection{Biosensor based in the insertion of non-natural amino-acids}

The use of amber stop codons has been allowed to acylate the tRNA with un-natural amino acids and enrich its chemical repertory into a protein. In addition to this method Honsaka and col has been developed the four base pare method to incorporate unnatural amino acids, among them have been synthesized $p$-aminophenylalanine derivatives bound to 
BODIPY fluorophore. This approach was applied to incorporate two variants of fluorescent amino acids to calmodulin, an energy donor acceptor pair, to demonstrate the feasibility for FRET measurements when the distance between pairs change upon addition of calmodulin binding protein. This method allowed to study in solution the dynamics of the conformational change of calmodulin.

\subsection{Biosensor based in post transcription modifications and chemical modification}

Introducing a fluorescent signal without knowing about the sequence or the three dimensional structure, or binding domains for obtain a functional biosensor could be a very hard task, Hamachi and collaborators introduce the post-photoaffinity labeling modification (P-PALM) to introduce fluorescent molecule close of the active site of a enzyme without any genetic manipulation to introduce the signal into the protein (Nagase, Nakata et al. 2003; Nakata, Nagase et al. 2004). The main goal of this methodology to attach fluorescent labels in living cells or whole organisms, that is the reason to avoid genetic methods. Based in this approach this group developed a biosensor based in the scaffold of a lectin, a saccharide binding protein. To this end concavalin A (Con A) was used in presence of the P-PALM reagent. This reagent have three important characteristics (Fig. 2): 1) high affinity to the lectine, a saccharide moiety, to bind the Con A, 2) the photoactive moiety (diazirine) to label the protein by photoirradiation, and 3) a disulfide group to remove the original ligand to bind to the protein and allow at the same time a reactive site for chemical modification (the thiol group).

In other words the P-PALM is bounded to the protein by UV light irradiation when the ligand is anchored to the binding site of ConA by the saccharide moiety, then a reduction of the probe, generate a reactive $\mathrm{SH}$ for covalent modification with a thiol-reactive fluorophore, such as dansyl or fluorescein groups, then this lectin is transformed in fluorescent biosensor to saccharide (Fig 3).

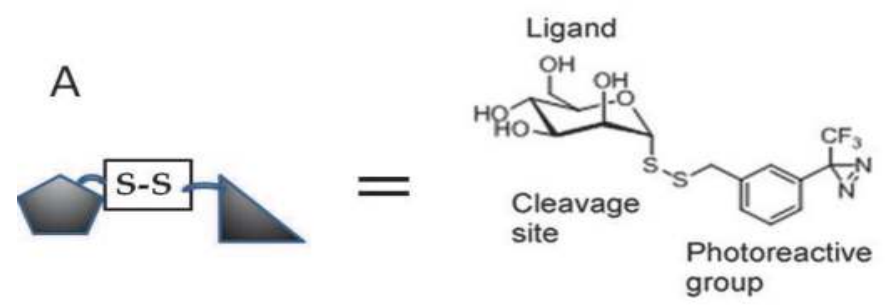

B

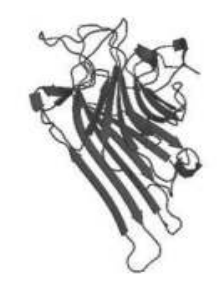

Fig. 2. P-PALM reactive and target. A is the molecular estructure of a post-photoaffinity labeling reagent P-PALM, and B is the structure of the target the concanalin A, the PDB Is is 1 VAM. 
The advantage of this method is the introduction of several chemical labels without need to use genetic engineered methods (Fig. 3), with the additional property to attach several fluorescent moieties. For example the addition of the fluorescent $\mathrm{pH}$ indicator, SNARF, the biosensor was able to distinguish to differentiate several anomeric groups present in the saccharides (Nakata, Nagase et al. 2004; Ojida, Miyahara et al. 2004). The same group of Hamachi and collaborators has been developed a similar methodology, now based in the chemistry of tosyl group, named ligand directed tosyl (LDT) chemistry (Tsukiji, Miyagawa et al. 2009) that contained benzenesulfoamide as the specific moiety. This allow to synthesize tosyl derivatives that bind specifically to some proteins: carbonic anhydrase, FK506-binding protein, or congerin (beta-galactoside-binding lectin). This strategy was applied successfully to create biosensor in vitro, and inside the cells without genetic modification methodology. The applications around this methodologies are versatile, for example another development by the same group is the quenched ligand directed toysil (Q-LDT) chemistry (Tsukiji, Miyagawa et al. 2009; Tsukiji, Wang et al. 2009; Wang, Nakata et al. 2009), in this case after the photolabeling, the fluorescent signal is quenched, but when the ligand interact in the binding site, the quencher is released from the protein, and the increase of fluorescence signal is used to do a calibration of the ligand concentration in solution.
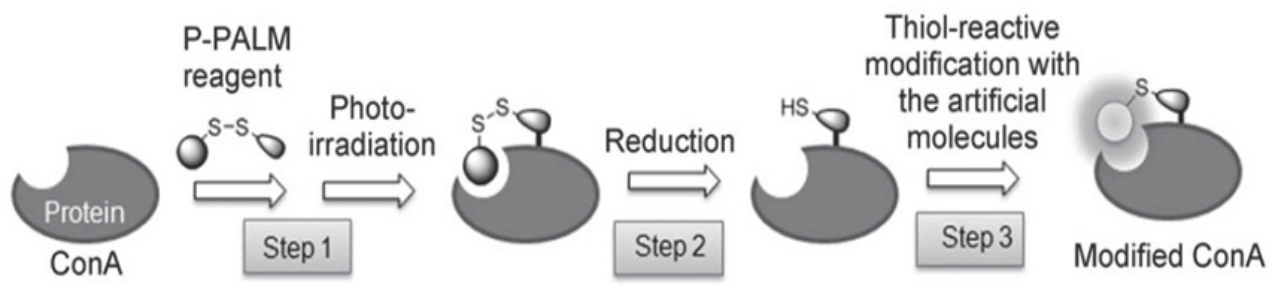

Fig. 3. Schema for the fluorescent labeling with a P-PALM reactive. In step 1 the P-PALM binds to the protein by photoirradiation, 2 reduction of the sample prepare a $\mathrm{SH}$ free and in 3 , the fluorophores by specific chemical modification to $\mathrm{SH}$ group.

\section{Biosensors for protein-ligand based in conformational changes}

Several protein changed the conformation locally of globally when a ligand binds, this is in part explained by the conformational displacement or induced fit mechanisms present in proteins. Accordingly to recent view for the dynamical properties of proteins, from nuclear magnetic resonance (NMR) and molecular dynamics algorithms, it have been proposed that proteins are in dynamical equilibrium, and the presence of ligand should stabilize one of the extreme states. In this dynamics equilibrium point of view, several non-covalent interactions, such as hydrogen bound, hydrophobic interactions or van del Walls interactions are created at expenses to remove other interactions in different part of the protein, in a coupled process to the ligand binding event, in this sense if a suitable fluorescent signal is located into protein carring out the conformational change, should be an ideal for biosensor design when a fluorescent transducer is attached to the protein. The family of periplasmic binding proteins (PBPs) that presented a conformational change upon 
ligand binding has been used to create diverse biosensors based in the fluorescent incorporation by chemical modification with thiol-fluorescent reactive for cysteine. This work has been pioneered by Cass and col by introduction of fluorescent group into the maltoside binding protein (MBP) a PBP, and extensively developed by Hellinga and collaborators (de Lorimier, Smith et al. 2002). This family of proteins presented a bilobated structure with high similarity, that present at least two conformers: an open form in absence of ligand and a closed state bound to its ligand (Fig. 4). Given that the different member of this family are able to bind a diverse number of ligands, it have been developed a big number of biosensor for diverse ligands such as glucose, ribose, aminoacid, ions etc.

In the same line of research Hellinga and col. have been employed member of PBPs to developed approximately 300 different biosensor, by introduction of the signal in the binding site, or near of remote from the binding site, for example into the hinge that connect the structure of the two lobules in PBPs.
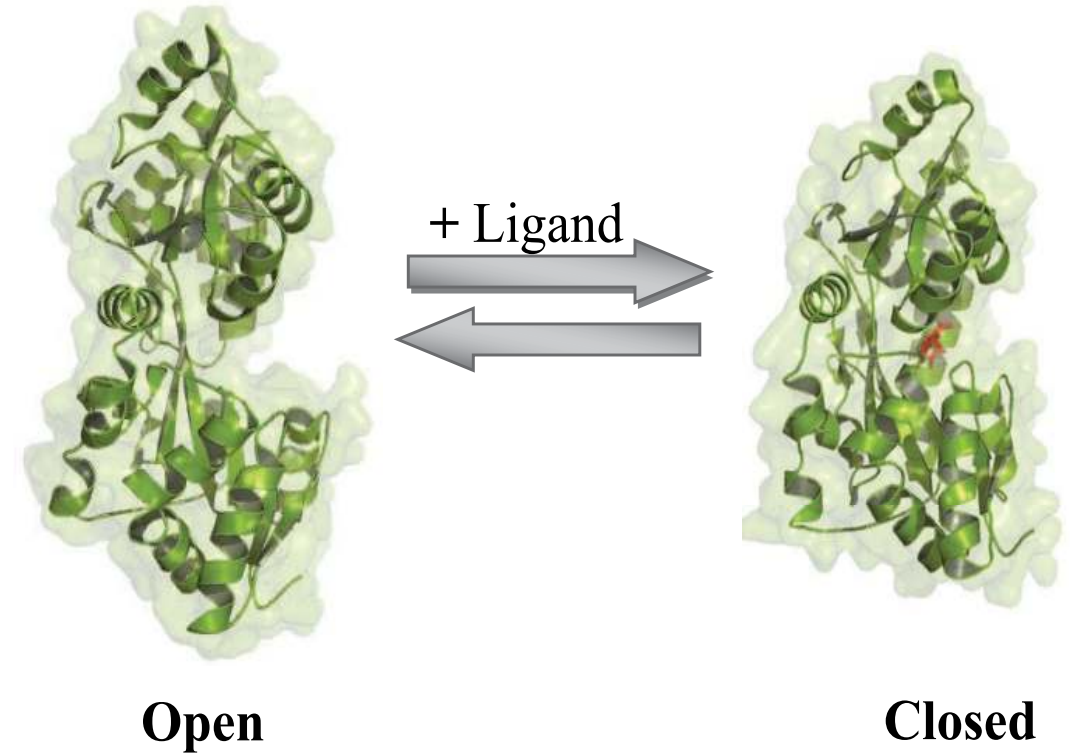

Fig. 4. Conformationa change present upon ligand binding in the maltoside binding protein, the PDD ID for open state is 1N3X and for the closed state is 1NL5.

The introduction of signal in the endosteric or allosteric sites allow to calibrate some of the signals to the concentration of ligand in solution, however only $4 \%$ of the 320 biosensor changed the fluorescence intensity to develop highly sensitive biosensor (Fig. 4). To improve the detection of the signal transduction, it was analyzed the molecular nature of fluorescence environment from a structural model for the maltose binding proteins and modified the fluorophore environment into the protein by site directed-mutagenesis, this study allow a increase in $400 \%$ of the signal intensity or signal, that point out the use of molecular modelling to improve the transduction signal to a high sensitive levels (Dattelbaum, Looger et al. 2005). 


\section{Biosensor to monitor protein-protein interactions}

Specific protein-protein interactions are required for cellular communication processes, such as signal transduction cascades, transcription events, or transport process, etc. The determination of crystallographic structure of the protein complexes is not necessarily enough to explain the molecular basis of their specific interactions, therefore for a more dynamic study of protein-protein interactions in solution is combined with the introduction of labels in or near of interaction surface for the protein complex with structural models. For example, the use of fluorescent labels covalently attached for the proteins that participate of the primary events during the coagulation cascade were carried out; the interaction of the extracellular tissue factor (soluble TF) and the activated factor VII (Owenius, Osterlund et al. 2001). The results of this work indicated that the multi-probe methodology permits to obtain indirect binding constants between the two proteins in solution, and it was concluded that the tightness of the local interactions at the labeled positions was similar to the interactions detected inside of the interior of globular proteins.

The interface of actin myosin complex monitored by site-directed fluorescence and spin labeling techniques revealed a more complicated point of view for the interacting forces required for the active complex formation (LaConte, Voelz et al. 2002). The hypothesis of a simple transition of disordered weak interactions to strong-ordered interactions during the actin-myosin complex was not consistent with experimental. A strong-complex formation was indicated by a decrease in the mobility of the labels, but the labeled myosin indicated high mobility even after complex formation, also, solvent accessibility surface was decreased for actin-bound labels although was increased for myosin-bound probes.

The photoreceptor rhodopsin present a conformational change activated by light in order to form an active state (named MII). This state, interact and activated the G protein transducin for the initiation of the biochemical cascade during the vision process (Filipek, Stenkamp et al. 2003). Interactions of both proteins were monitored by the changes in the fluorescence of bimane specifically incorporated into the rhodopsin, with the carboxylic terminus of a $G$ protein transducin (Janz and Farrens 2004), given that the tryptophan residue quenches the bimane fluorescence (Mansoor, McHaourab et al. 2002), this interaction is able to monitor protein-protein interactions or conformational changes in proteins. Mapping the interaction of tryptophan with bimane by fluorescence quenching in solution between rhodopsin and transducin, was detected the presence of a critical hydrophobic interaction that controls the affinity of this specific interaction (Janz and Farrens 2004). In a similar study for the binding and release of the arrestin to the photoreceptor rhodopsin were monitored in real time by the changes in the fluorescence spectra of arrestin labeled with bromobimane at the proposed surface-binding site of rhodopsin with the arrestin (Janz and Farrens 2004). These studies proposed that arrestin and retinal release from the rhodopsin receptor are a linked process (Sommer, Smith et al. 2005); thus, this innovative methodology has been used for study the dynamics of arrestin interactions on the mechanism of G-protein-coupled receptors (Sommer, Smith et al. 2006) which are the target of a big number of drugs designs.

\section{Biosensor for robust detection of ligand interactions and drug design}

Calmoduilin is a calcium binding proteins that interact with many cellular targets including soluble enzymes, ion-channels and primary pumps, resulting in a variety of essential 
downstream cellular effects (O'Neil and DeGrado 1990; Weinstein and Mehler 1994; Zhang and Yuan 1998; Zielinski 1998; Carafoli and Klee 1999; Berridge, et al. 2003), and the conformation of the protein which drastically change according to the calcium levels into the cell to regulate physiological processes (Fig. 5), therefore this protein represents an important drug target (Dagher, et al. 2006). Indeed, many CaM inhibitors are well known antipsychotic, smooth muscle relaxants, antitumoral and $\alpha$-adrenergic blocking agents, among others. The interaction of $\mathrm{CaM}$ with its physiological targets depends on the exposure of two hydrophobic pockets (Fig. 5) following the conformational change elicited by $\mathrm{Ca}^{2+}$-binding to the protein.

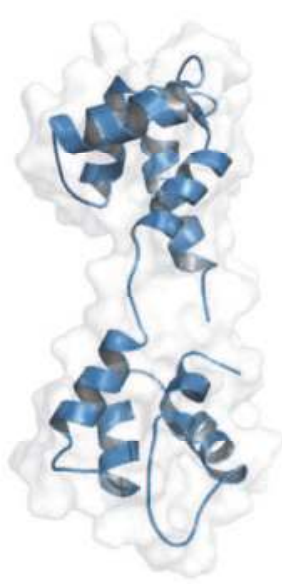

A

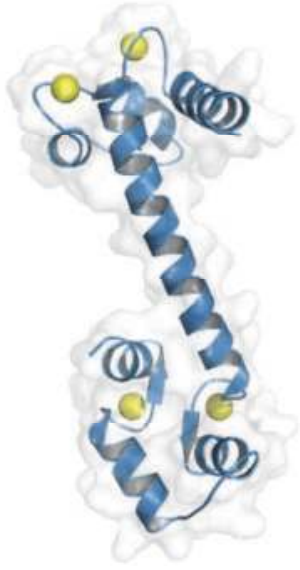

B
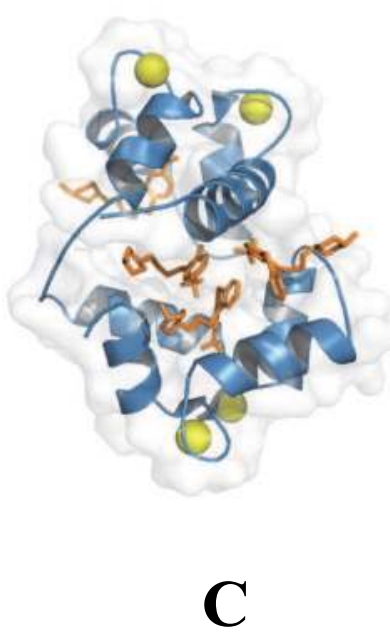

Fig. 5. Three-dimensional structures of the CaM in its different conformations: A) calciumfree ( $p d b$ code: 1CFD); B) with calcium ( $p d b$ code: 1CLL) and; C) with TFP (pdb code: 1LIN). The structures were drawn using the PyMOL program.

Many compounds including drugs, pesticides and research tools interact with CaM at the same hydrophobic sites provoking also conformational changes in the protein. Many of these substances behave as CaM antagonists, the best known structural examples of these interactions are the antipsychotic analogs of trifluoroperazine (Gangopadhyay, et al. 2004). In this sense several CaM has been used a protein target to interact with several protein by fluorescent attachment, for example: interaction between calmodulin (CaM) and a CaMbinding peptide of the ryanodine receptor (CaMBP) and its sub-fragments F1, has been measured by the mutant Thr31Cys with the fluorescent group badan attached (Sharma, Deo et al. 2005). A mutant of CaM coupled to three different environment-sensitive fluorophores (MDCC, acrylodan, and IANBD ester) was detected the CaM interaction with phenothiazines and related tryclic antidepressants (Douglass, Salins et al. 2002). Recently Gonález-Andrade and col, has been designed a alternative biosensing assay for CaM inhibitors by chemical modification of bromobimane at position 124 (Gonzalez-Andrade, et al. 2009; Figueroa, et al. 2010), that allowed to determine the $\mathrm{IC}_{50}$ and $K_{d}$ of the CaM inhibitors in a same fluorescent assay Fig 6. 

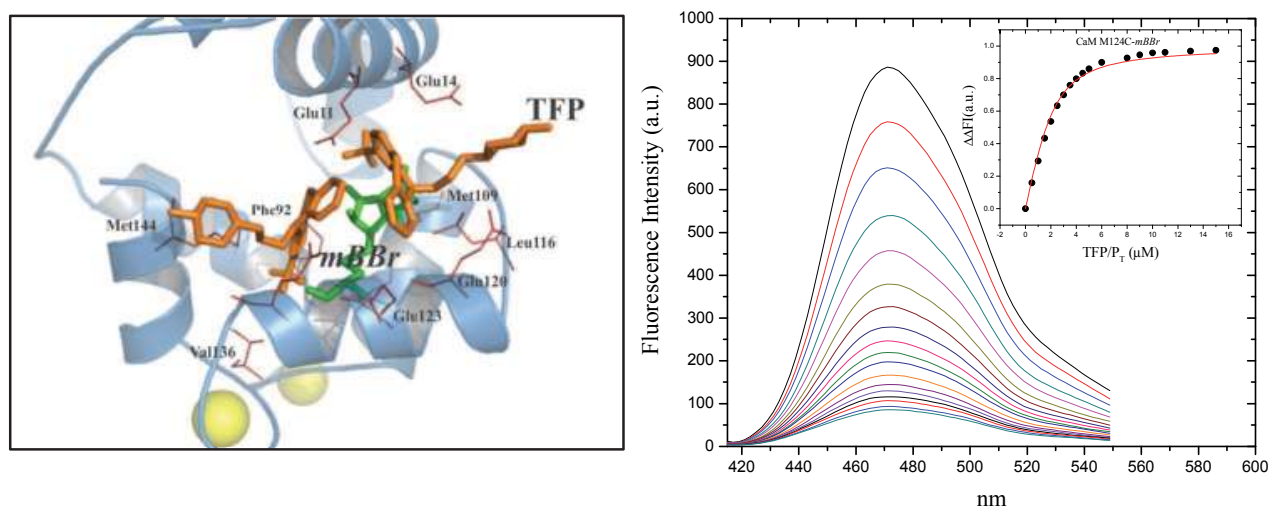

Fig. 6. Structural moeling of the trifluoroperazine into the binding site of calmodulin and fluoresence titration to compare with fluorescent changes.

\section{Conclusions}

The well established method to attach fluorescent labels into the structure of a protein mentioned above by chemical methods in combination in some cases with the molecular biology methodologies, is making available a broad number of proteins to monitor a diverse protein interactions. The selection of a protein receptor that should be a target form drug design for example the case of G protein coupled receptors (GPCR), that represent close of the $30 \%$ of the drug market, or calmoduilin that participates in a large number of protein signals, provided a excellent protein receptor to be adapted in robust protein immobilization methods required in the development of new strategies in the drug research by high throughput screening.

\section{Acknowledgments}

This work was partially supported by grant 53633 from CONACYT, México. Martin González-Andrade acknowledges postdoctoral fellowship, awarded by DGAPA-UNAM.

\section{References}

Altenbach, C., J. Klein-Seetharaman, et al. (1999). Structural features and light-dependent changes in the sequence 59-75 connecting helices I and II in rhodopsin: a sitedirected spin-labeling study. Biochemistry 38(25): 7945-7949.

Berridge, M. J., M. D. Bootman, et al. (2003). Calcium signalling: dynamics, homeostasis and remodelling. Nat Rev Mol Cell Biol 4(7): 517-529.

Campbell, R. E. (2009). Fluorescent-protein-based biosensors: modulation of energy transfer as a design principle. Anal Chem 81(15): 5972-5979.

Carafoli, E. and C. B. Klee (1999). Calcium as a cellular regulator. New York, Oxford University Press.

Cooper, M. A. (2003). Biosensor profiling of molecular interactions in pharmacology. Curr Opin Pharmacol 3(5): 557-562. 
Dagher, R., C. Pigault, et al. (2006). Use of a fluorescent polarization based high throughput assay to identify new calmodulin ligands. Biochim Biophys Acta 1763(11): 12501255.

Dattelbaum, J. D., L. L. Looger, et al. (2005). Analysis of allosteric signal transduction mechanisms in an engineered fluorescent maltose biosensor. Protein Sci 14(2): 284291.

de Lorimier, R. M., J. J. Smith, et al. (2002). Construction of a fluorescent biosensor family. Protein Sci 11(11): 2655-2675.

de Lorimier, R. M., Y. Tian, et al. (2006). Binding and signaling of surface-immobilized reagentless fluorescent biosensors derived from periplasmic binding proteins. Protein Sci 15(8): 1936-1944.

Deuschle, K., S. Okumoto, et al. (2005). Construction and optimization of a family of genetically encoded metabolite sensors by semirational protein engineering. Protein Sci 14(9): 2304-2314.

Douglass, P. M., L. L. Salins, et al. (2002). Class-selective drug detection: fluorescentlylabeled calmodulin as the biorecognition element for phenothiazines and tricyclic antidepressants. Bioconjug Chem 13(6): 1186-1192.

Figueroa, et al. (2010). Fluorescence, circular dichroism, NMR, and docking studies of the interaction of the alkaloid malbrancheamide with calmodulin. J Enzyme Inhib Med Chem.

Filipek, S., R. E. Stenkamp, et al. (2003). G protein-coupled receptor rhodopsin: a prospectus. Annu Rev Physiol 65: 851-879.

Gangopadhyay, J. P., Z. Grabarek, et al. (2004). Fluorescence probe study of Ca2+dependent interactions of calmodulin with calmodulin-binding peptides of the ryanodine receptor. Biochem Biophys Res Commun 323(3): 760-768.

Gonzalez-Andrade, M., M. Figueroa, et al. (2009). An alternative assay to discover potential calmodulin inhibitors using a human fluorophore-labeled CaM protein. Anal Biochem 387(1): 64-70.

Janz, J. M. and D. L. Farrens (2004). Rhodopsin activation exposes a key hydrophobic binding site for the transducin alpha-subunit C terminus. J Biol Chem 279(28): 29767-29773.

LaConte, L. E., V. Voelz, et al. (2002). Molecular dynamics simulation of site-directed spin labeling: experimental validation in muscle fibers. Biophys J 83(4): 1854-1866.

Looger, L. L., M. A. Dwyer, et al. (2003). Computational design of receptor and sensor proteins with novel functions. Nature 423(6936): 185-190.

Mansoor, S. E. and D. L. Farrens (2004). High-throughput protein structural analysis using site-directed fluorescence labeling and the bimane derivative (2pyridyl)dithiobimane. Biochemistry 43(29): 9426-9438.

Mansoor, S. E., H. S. McHaourab, et al. (2002). Mapping proximity within proteins using fluorescence spectroscopy. A study of T4 lysozyme showing that tryptophan residues quench bimane fluorescence. Biochemistry 41(8): 2475-2484.

Medintz, I. L. and J. R. Deschamps (2006). Maltose-binding protein: a versatile platform for prototyping biosensing. Curr Opin Biotechnol 17(1): 17-27.

Nagase, T., E. Nakata, et al. (2003). Construction of artificial signal transducers on a lectin surface by post-photoaffinity-labeling modification for fluorescent saccharide biosensors. Chemistry 9(15): 3660-3669. 
Nakata, E., T. Nagase, et al. (2004). Coupling a natural receptor protein with an artificial receptor to afford a semisynthetic fluorescent biosensor. J Am Chem Soc 126(2): 490-495.

O'Neil, K. T. and W. F. DeGrado (1990). How calmodulin binds its targets: sequence independent recognition of amphiphilic alpha-helices. Trends Biochem Sci 15(2): 59-64.

Ojida, A., Y. Miyahara, et al. (2004). Recognition and fluorescence sensing of specific amino acid residue on protein surface using designed molecules. Biopolymers 76(2): 177184.

Owenius, R., M. Osterlund, et al. (2001). Spin and fluorescent probing of the binding interface between tissue factor and factor VIIa at multiple sites. Biophys J 81(4): 2357-2369.

Plaxco, K. W. and H. T. Soh (2011). Switch-based biosensors: a new approach towards realtime, in vivo molecular detection. Trends Biotechnol 29(1): 1-5.

Sharma, B., S. K. Deo, et al. (2005). Competitive binding assay using fluorescence resonance energy transfer for the identification of calmodulin antagonists. Bioconjug Chem 16(5): 1257-1263.

Sommer, M. E., W. C. Smith, et al. (2005). Dynamics of arrestin-rhodopsin interactions: arrestin and retinal release are directly linked events. J Biol Chem 280(8): 6861-6871.

Sommer, M. E., W. C. Smith, et al. (2006). Dynamics of arrestin-rhodopsin interactions: acidic phospholipids enable binding of arrestin to purified rhodopsin in detergent. J Biol Chem 281(14): 9407-9417.

Tsukiji, S., M. Miyagawa, et al. (2009). Ligand-directed tosyl chemistry for protein labeling in vivo. Nat Chem Biol 5(5): 341-343.

Tsukiji, S., H. Wang, et al. (2009). Quenched ligand-directed tosylate reagents for one-step construction of turn-on fluorescent biosensors. J Am Chem Soc 131(25): 9046-9054.

Vallee-Belisle, A. and K. W. Plaxco (2010). Structure-switching biosensors: inspired by Nature. Curr Opin Struct Biol 20(4): 518-526.

Wang, H., E. Nakata, et al. (2009). Recent progress in strategies for the creation of proteinbased fluorescent biosensors. Chembiochem 10(16): 2560-2577.

Weinstein, H. and E. L. Mehler (1994). Ca(2+)-binding and structural dynamics in the functions of calmodulin. Annu Rev Physiol 56: 213-236.

Zhang, M. and T. Yuan (1998). Molecular mechanisms of calmodulin's functional versatility. Biochem Cell Biol 76(2-3): 313-323.

Zielinski, R. E. (1998). Calmodulin and Calmodulin-Binding Proteins in Plants. Annu Rev Plant Physiol Plant Mol Biol 49: 697-725. 


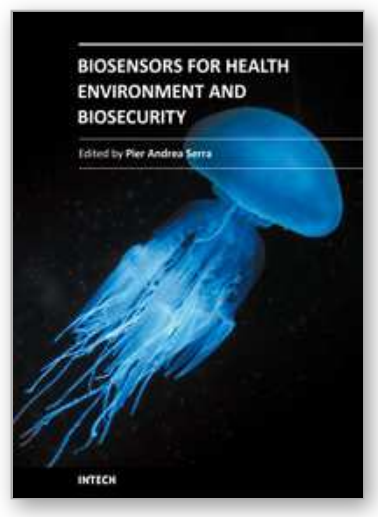

\author{
Biosensors for Health, Environment and Biosecurity \\ Edited by Prof. Pier Andrea Serra
}

ISBN 978-953-307-443-6

Hard cover, 540 pages

Publisher InTech

Published online 19, July, 2011

Published in print edition July, 2011

\begin{abstract}
A biosensor is a detecting device that combines a transducer with a biologically sensitive and selective component. Biosensors can measure compounds present in the environment, chemical processes, food and human body at low cost if compared with traditional analytical techniques. This book covers a wide range of aspects and issues related to biosensor technology, bringing together researchers from 16 different countries. The book consists of 24 chapters written by 76 authors and divided in three sections: Biosensors Technology and Materials, Biosensors for Health and Biosensors for Environment and Biosecurity.
\end{abstract}

\title{
How to reference
}

In order to correctly reference this scholarly work, feel free to copy and paste the following:

Alejandro Sosa-Peinado and Martín González-Andrade (2011). Fluorescent Biosensors for Protein Interactions and Drug Discovery, Biosensors for Health, Environment and Biosecurity, Prof. Pier Andrea Serra (Ed.), ISBN: 978-953-307-443-6, InTech, Available from: http://www.intechopen.com/books/biosensors-for-healthenvironment-and-biosecurity/fluorescent-biosensors-for-protein-interactions-and-drug-discovery

\section{INTECH}

open science | open minds

\section{InTech Europe}

University Campus STeP Ri

Slavka Krautzeka 83/A

51000 Rijeka, Croatia

Phone: +385 (51) 770447

Fax: +385 (51) 686166

www.intechopen.com

\section{InTech China}

Unit 405, Office Block, Hotel Equatorial Shanghai

No.65, Yan An Road (West), Shanghai, 200040, China

中国上海市延安西路 65 号上海国际贵都大饭店办公楼 405 单元

Phone: +86-21-62489820

Fax: +86-21-62489821 
(C) 2011 The Author(s). Licensee IntechOpen. This chapter is distributed under the terms of the Creative Commons Attribution-NonCommercialShareAlike-3.0 License, which permits use, distribution and reproduction for non-commercial purposes, provided the original is properly cited and derivative works building on this content are distributed under the same license. 